\title{
Hematopoietic colony-stimulating factors: new players in tumor-nerve interactions
}

\author{
Sebastian Stösser • Matthias Schweizerhof • \\ Rohini Kuner
}

Received: 9 May 2010 /Revised: 2 October 2010 / Accepted: 28 October 2010 /Published online: 16 November 2010

(C) The Author(s) 2010. This article is published with open access at Springerlink.com

\begin{abstract}
A variety of cancers are accompanied by debilitating pain, which constitutes the primary reason for poor quality of life in cancer patients. There is an urgent demand for the development of specific mechanism-based therapies against cancer pain. Recently, important advances have been made in mechanisms contributing to cancer pain. A notable finding was that the tumor-derived hematopoietic growth factors, granulocyte- and granulocyte-macrophagecolony-stimulating factors (G-CSF/GM-CSF), subserve important functions in the generation of pain hypersensitivity in tumor-affected regions. In this context, their receptors were unexpectedly found on pain-sensing nerves and were observed to be functionally linked to nociceptive sensitization and tumor-induced pain. Here, we review evidence supporting a role for G-/GM-CSF in sensitization of pain-sensing nerves, the underlying signaling pathways and the cross-talk with other pronociceptive cytokines, peptides and modulators derived from immune cells, osteoclasts and tumor cells. These findings hold implications in the therapy of pain in disease states, such as cancer and rheumatoid arthritis.
\end{abstract}

Keywords Cancer pain · G-CSF - GM-CSF - Hyperalgesia . Peripheral sensitization

S. Stösser $\cdot$ M. Schweizerhof $\cdot$ R. Kuner $(\triangle)$

Pharmacology Institute, University of Heidelberg,

Im Neuenheimer Feld 366,

69120, Heidelberg, Germany

e-mail: rohini.kuner@pharma.uni-heidelberg.de

\section{Introduction}

Approximately one third of adults who are actively receiving treatment for cancer and two thirds of those with advanced malignant disease experience pain [1]. Children with cancer have similar experiences, which is why the International Association for the Study of Pain (IASP) defined the year 2008-2009 as a global year against cancer pain. In a large number of clinical cases, cancer-associated pain, particularly the neuropathic component thereof, is resistant to conventional therapeutics or their application is severely limited owing to the widespread side effects $[1,2]$. In order to develop novel, mechanism-based therapeutic strategies, it is imperative to delineate the cellular and molecular mechanisms underlying cancer-induced pain. Unlike pain of neuropathic or inflammatory origin, cancer pain has not been widely studied [2,3]. Well-characterized animal models, which merge pain research and cancer research, have only recently become available and now provide a platform for interdisciplinary research [2-4]. These studies have revealed that although tumor-induced pain shares features of inflammatory as well as neuropathic pain, it is clearly distinguished by distinct pathophysiological and mechanistic aspects $[3,4]$.

Various types of carcinomas and sarcomas metastasize to skeletal bones and cause spontaneous bone pain, hyperalgesia (exaggerated pain) and allodynia (pain in response to a normally innocuous stimulus), which is accompanied by bone degradation and remodelling of peripheral nerves $[3,4]$. A cardinal feature of cancer pain is the involvement of mediators secreted by tumor cells (tumor-associated mediators) $[2,3]$. These include growth factors, cytokines and peptides, which have the potential of either directly activating nociceptive nerves or sensitizing them towards sensory stimuli. The identity of tumor-associated mediators and precisely how they affect sensory nerve function is an 
area of research which carries immense promise in understanding and treating cancer pain. For example, a variety of tumors of myeloid and non-myeloid origin secrete large quantities of the cytokines, granulocyte-colonystimulating factor (G-CSF) and granulocyte/macrophagecolony-stimulating factor (GM-CSF) [5]. Here, we will review evidence supporting a novel role for G-/GM-CSF in pain associated with cancer and inflammation and we will discuss potential underlying mechanisms.

\section{A novel role for G-CSFR and GM-CSFR $\alpha$ in cancer pain}

A recent study has, for the first time, functionally linked G-/ GM-CSF secreted by tumor cells in bone metastases to sensitization of pain-sensing nerves (nociceptors) and tumorevoked pain [6]. Although G-/GM-CSF receptors (G-/GMCSFR) and G-/GM-CSF signaling are classically associated with modulation of hematopoietic and tumor cells, three independent lines of evidence extend the range of G-/GMCSF signaling to sensory nerves: (1) protein and mRNA analyses reveal expression of G-CSFR and the alpha-subunit of GM-CFSR (GM-CSFR $\alpha$ ) in sensory nerves in peripheral tissues, including cancerous pancreas and bone matrix/ periosteum, as well as in their somata lying in the dorsal root ganglia (DRG). (2) Exposure to G-/GM-CSF activates their cognate receptors and their typical signaling pathways in DRG neurons and leads to potentiation of neuropeptide release from nociceptive neurons. (3) Exposure to G-/GMCSF sensitizes sensory nerves to nociceptive stimuli, which can be observed at the level of activity of single nerves in electrophysiological analyses ex vivo as well as the level of behavioral responses to noxious stimuli in vivo. These observations are highly suggestive of activation of receptors on sensory nerves by tumor-derived G-/GM-CSF. Indeed, blocking G-/GM-CSFR signaling by receptor neutralising antibodies or via signaling inhibitors leads to an abrogation of bone tumor-induced pain hypersensitivity; however, these treatments also partially affect tumor growth, raising the question as to whether pain reduction is only secondary to reduced tumor growth. A key finding was that specific downregulation of GM-CSFR $\alpha$ in DRG neurons specifically reduces tumor-induced pain hypersensitivity without affecting tumor growth, indicating thereby that GM-CSFR $\alpha$ signaling in sensory nerves is causally linked to cancer pain.

\section{Signaling mechanisms linking G-/GM-CSFR to nociceptor sensitization}

Receptors for G-CSF and GM-CSF can signal via multiple pathways and diverse signaling mediators may be employed in different cell types $[5,7,8]$ (see Figs. 1 and 2). The GMCSF receptor is a heterodimer consisting of the ligandbinding $\alpha$-subunit, which is specific for GM-CSFR, and the signal transducing $\beta$-subunit, which is shared with the receptors for IL-3 and IL-5 [5]. G-CSFR is a typical class I cytokine receptor [5].

The three main signaling pathways, which are activated by G-/GM-CSF and mediate their functions in hematopoietic cells, include the Janus kinase-signal transducer and activator of transcription (JAK-STAT) pathway, the mitogen-activated protein kinase (MAPK) pathway and the phosphoinositide 3kinase (PI3K) pathway [5, 8], all of which have been directly or indirectly implicated in pain modulation (see below). Furthermore, G- and GM-CSFR are also able to signal via other mechanisms like activation of phospholipases or changes in cyclic nucleotide levels [7], which seem to be of marginal importance for G-/GM-CSF functions in hematopoietic cells, but could be essential for signaling in nociceptors. Possible links between signaling pathways stimulated by G-/GM-CSF and sensitization of nociceptors are highlighted below and represented schematically in Figs. 1 and 2.

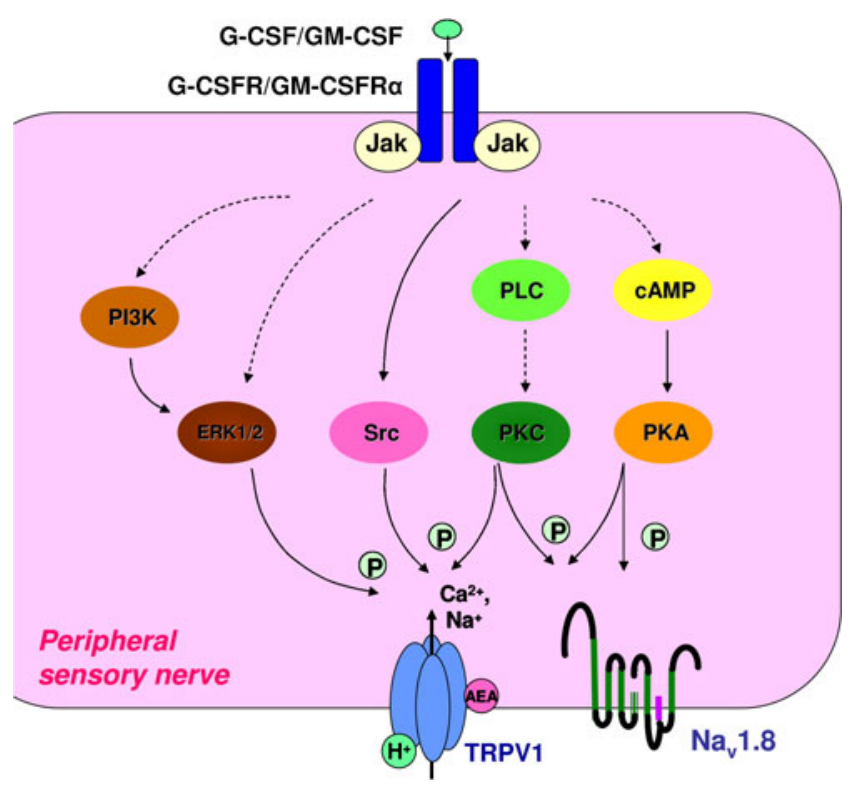

Fig. 1 Schematic representation of potential signaling mechanisms linking transmembrane receptors for G-CSF and GM-CSF to sensitization of nociceptive transducers in peripheral sensory neurons. Binding of G-CSF or GM-CSF to their cognate transmembrane receptors can activate a myriad of signaling cascades resulting ultimately in sensitization and increased membrane levels of TRPV1 and $\mathrm{Na}_{\mathrm{v}} 1.8$, which representatively depicts the process of nociceptor sensitization here. TRPV1 transduces heat, protons and lipids, such as anandamide $(A E A)$ and $\mathrm{Na}_{\mathrm{v}} 1.8$ is a key determinant of nociceptor excitability. The MAP kinases ERK1/2, Src kinases, protein kinase $\mathrm{C}$ $(P K C)$ and protein kinase A $(P K A)$ modify either the function of TRPV1 or its membrane localisation via phosphorylation. Signaling cascades stimulated differentially by G-CSF and GM-CSF are not depicted separately here. Dotted arrow lines indicate that intermediate steps of the signaling cascade were omitted in the representation 


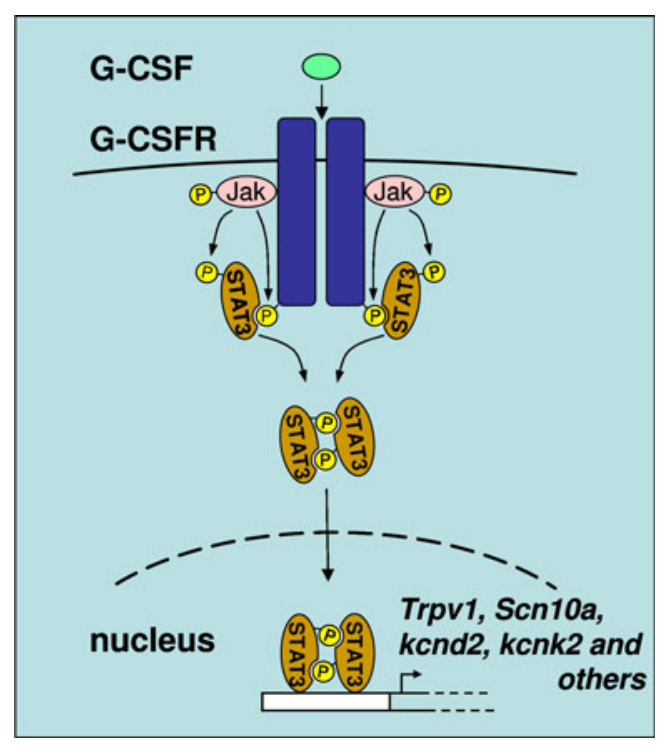

Fig. 2 Further implications of G-/GM-CSF-induced JAK-STAT signaling in peripheral sensory neurons. G-/GM-CSF induces nuclear translocation of STAT3 and promotes the transcription of genes encoding TRPV1 (Trpv1), $\mathrm{Na}_{\mathrm{v}} 1.8$ (Scn10a), $\mathrm{K}_{\mathrm{v}} 4.2$ (kcnd2), TREK-1 $(k c n k 2)$ and possibly other pain-related genes via the JAK-STAT pathway

Sensitization processes in nociceptors often involve potentiation of nociceptive transducers, such as the ion channels of the transient receptor potential (TRP) family. For example, the vanilloid receptor TRPV1, a sensor of noxious heat, protons and lipid algogens is potentiated via phosphorylation by diverse protein kinases, including the protein kinase $\mathrm{C}$ (PKC) and the non-receptor tyrosine kinase, Src, amongst others [9-11] (Fig. 1). Increased excitability can also come about by enhanced membrane expression of nociceptive transducers or transcriptional upregulation of key modulators. Prominent amongst the latter are tetrodotoxin-resistant sodium channels, such as $\mathrm{Na}_{\mathrm{v}} 1.8$, which specifically impart nociceptors with their characteristic activation properties $[9,11]$ (Fig. 1). The activation properties of nociceptors may also be changed by shifts in the membrane potential, e.g. via modulation of potassium channels. Long-lasting sensitization of nociceptors can also be accompanied by structural changes, e.g. sprouting of peripheral terminals.

Activation of the JAK-STAT pathway by G-/GM-CSF leads to the activation of the STAT family transcription factors, which dimerize and translocate to the nucleus upon activation and modulate gene expression $[5,8,12]$. In cultured DRG neurons, STAT3 is rapidly phosphorylated and translocates to the cell nucleus upon exposure to G-/ GM-CSF [6] (Fig. 2). However, the targets of STAT3 in pain-sensing neurons remain unknown. So far, G-CSF treatment has been reported to enhance the expression of nociceptive transducers such as TRPV1, $\mathrm{Na}_{\mathrm{v}} 1.8$ and potassium channels which are involved in regulating excitability of sensory nerves, such as $\mathrm{K}_{\mathrm{v}} 4.2$ in cultured DRG neurons [6] (Fig. 2). G-/GM-CSF signaling in nociceptors was associated with hyperalgesia to thermal and mechanical stimuli. However, it has not been worked out which of the above targets of G-/GM-CSF signaling mediate modulation of which modality of nociception and further studies are required to address this important question. The modulation of TRPV1 expression by CSF signaling in sensory neurons is particularly interesting since TRPV1 is an important mediator of pain evoked by tissue acidosis, which is frequently observed in tumor-affected tissues. Although TRPV1 is primarily associated with thermal hyperalgesia, some studies have also linked it to mechanical hyperalgesia under certain pain conditions [13-16]. Blocking TRPV1 has been reported to alleviate tumor pain [14]. Unfortunately, therapy with TRPV1 antagonists appears to be problematic on account of hyperthermia, which has been reported in clinical trials [17]. Another interesting aspect is that STAT3 signaling in sensory nerves has been implicated in structural changes, such as enhancement of neurite outgrowth in cultured DRG neurons [18] and regeneration [19]. This raises the possibility that STAT3 may mediate G-/GM-CSF-induced nerve remodelling which was observed in cultured DRG neurons as well as in tumor-affected mouse paw in vivo [6].

The two other main signaling mechanisms of G-/GM-CSF, the MAPK pathway and the PI3K pathway, are also promising candidates for mediating G-/GM-CSF-induced hyperalgesia. PI3K and MAP kinases, such as the extracellular signal regulated kinases 1 and 2 (ERK1/2) and p38, have both been strongly implicated in sensitization of peripheral sensory neurons [9, 20-22]. In cultured DRG neurons, application of G-/GM-CSF leads to a rapid activation and nuclear translocation of ERK1/2 in a PI3K-dependent manner, which is highly interesting in the light of a study showing that the PI3K-ERK pathway induces heat hyperalgesia by sensitizing TRPV1 [21].

G-/GM-CSF also activate signaling pathways less known for their functions in hematopoietic cells, but strongly involved in peripheral sensitization. Colony-stimulating factors are able to stimulate guanine nucleotide-binding proteins ( $\mathrm{G}$ proteins) [7]. Most notably in this context is a study showing that GM-CSF stimulates G-protein activity in a cholera toxin-sensitive manner and increases levels of cyclic adenosine monophosphate (cAMP) in T lymphocytes [23]. This suggests an involvement of Gs proteins with subsequent increase of cAMP possibly followed by activation of protein kinase A (PKA). This pathway plays a predominant role in sensitization of nociceptors and mediates the action of well-known algesic agents, such as prostaglandins and bradykinin [24-26], which cause phosphorylation of key ion channels such as TRPV1 and $\mathrm{Na}_{\mathrm{v}} 1.8$ via PKA [27, 28] (Fig. 1). However, whether a 
cAMP-PKA pathway contributes to G-/GM-CSF-induced hyperalgesia has yet to be addressed.

Another well-investigated mechanism of nociceptor sensitization is the activation of phospholipase $\mathrm{C}$ downstream of G-protein-coupled receptors or receptor tyrosine kinases $[9,11]$. This leads to the breakdown of phosphatidyl inositol 4,5-bisphosphate, which subsequently increases membrane levels of diacylglycerol and cytosolic levels of inositol 1,4,5-trisphosphate followed by activation of PKC. All of these signaling components are involved in sensitization of pain-related ion channels, such as TRPV1 [29-31]. Moreover, PKC can increase membrane levels of TRPV1 by stimulating membrane insertion [32] (Fig. 1). In hematopoietic cells, the PLC-PKC pathway is activated by G-/GM-CSF [33-36], suggesting that G-/GM-CSF may also stimulate this pathway in nociceptive neurons. In particular, the isoform $\mathrm{PKC}-\varepsilon$ seems to be solely essential for function in human bone marrow cells [37]. Interestingly the same isoform, $\mathrm{PKC}-\varepsilon$, is critical for sensitization of TRPV1 and $\mathrm{Na}_{\mathrm{v}} 1.8$ in nociceptors $[29,38,39]$. However, the role of PLC-PKC signaling in G-/GM-CSF-induced hyperalgesia still remains to be investigated. The cAMP binding protein Epac has been reported to link the cAMP/ PKA and PLC/PKC pathways [40, 41]. Whether this important form of cross-talk between these two key pathways in nociceptor sensitization comes about following G-/GMCSF exposure in chronic pain states is not known. Furthermore, G-CSF is able to activate kinases of the Src family [42, 43]. Src kinases have been shown to sensitize TRPV1 [10]. This creates another likely link between colony-stimulating factor signaling and sensitization of nociceptors.

Addressing precise mechanisms via which G-/GM-CSF signaling potentiates pain and nerve remodeling may be important in understanding the mechanisms of cancer pain and their therapeutic modulation. For example, it will be interesting to address which nociceptive mediators and ionchannel transducers are modulated by G-/GM-CSF signaling in sensory neurons and whether the repertoire of activated signaling components is different in sensory neurons versus hematopoietic cells. Indeed, this could represent one way to enable targeting G-/GM-CSF receptors on pain-sensing nerves devoid of side effects on the hematopoietic system, such as neutropenia.

\section{The role of G-/GM-CSF in bone morphology and bone pain}

G-CSF and GM-CSF are widely used in clinical practice for their stimulating properties on proliferation and release of myeloid lineage cells into the blood stream [8]. Clinical indications for therapy with these colony-stimulating factors include prevention and treatment of neutropenia associated with myelosuppressive chemotherapy, reconstitution after bone marrow transplantion and mobilization of hematopoietic progenitor cells for transplantation of peripheral blood progenitor cells. Numerous clinical studies have documented adverse drug reactions upon clinical usage of G-CSF and GM-CSF, the most frequent and acutely harmful adverse event being intense bone pain. Reported frequencies reach up to $90 \%$ [44-46], making bone pain a serious problem of a therapy with G-/GM-CSF. The findings of a role for G-/GM-CSF receptors expressed on sensory neurons in nociceptor sensitization can directly account for this poorly understood clinical observation [6]. Additional potential mechanisms arise from studies focusing on the effect of G-CSF on bone metabolism. While long-term application of G-CSF may lead to osteoporosis [47], short-term effects on bone metabolism are less clear. One study demonstrated decreased serum levels of osteocalcin and increased levels of bone-specific alkaline phosphatase following short-term (5 days) G-CSF application in healthy blood progenitor cell donors [48]. This particular regulatory pattern of bone metabolism parameters has been described in patients with osteolytic bone metastases [49]. Osteolytic bone metastases are well known to cause pain partly by activation of osteoclasts and local acidosis [50]. Furthermore, bisphosphonates, a class of drugs inhibiting osteoclast activity, can ease bone metastases-induced cancer pain [51]. Thus, changes in bone metabolism induced by G-CSF may represent a bone-specific mechanism by which G-CSF causes bone pain, in addition to direct effects on sensory neurons as described recently [6]. This concept is in line with the findings that tumor-derived G-CSF plays a crucial role in a mouse model of cancer pain induced by osteolytic bone metastases [6].

\section{Implications for G-/GM-CSF signaling in inflammatory pain states}

In addition to a role in cancer biology, G-/GM-CSF signaling has been implicated in the modulation of immune function. G-CSF and GM-CSF are locally released following tissue injury [52] or inflammation [53] and diverse functions have been ascribed to them in modulating local and systemic inflammatory responses [5]. Furthermore, G-/ GM-CSF may locally contribute to inflammatory pain by directly sensitizing peripheral nerves. Indeed, G-CSF and GM-CSF levels are elevated in wound exudates of women having undergone caesarean delivery [52]. Interestingly, analgesic consumption during the first $24 \mathrm{~h}$ after surgery was found to be inversely proportional to G-CSF levels in the wound exudate [52], suggesting that CSF signaling is indeed functionally linked to exaggerated pain in humans. 
G-CSF and GM-CSF may also contribute to opioidinduced hyperalgesia, i.e. heightened pain sensitivity after chronic use of opioids. One study demonstrated that cytokine skin levels, including G-CSF, and pain sensitivity are elevated in a mouse model of postincisional pain following long-term application of morphine [54]. These results may be explained on a mechanistic basis by sensitization of peripheral nerves by colony-stimulating factors. In rheumatoid arthritis, a systemic inflammatory disorder characterized by joint pain, G-CSF and GM-CSF levels are also highly elevated [55-57]. G-CSF and GM-CSF are implicated in the pathogenesis of rheumatoid arthritis [58-60] and are considered as promising therapeutic targets [61].

\section{Cross-talk between G-/GM-CSF and other immune modulators of pain}

A very interesting and relevant aspect in the context of tumor-nerve interactions constitutes the potential cross-talk between hematopoietic growth factors and several of the previously identified paracrine mediators of cancer pain and immune disorders. These include cytokines, such as tumor necrosis factor $\alpha(\mathrm{TNF}-\alpha)$ and interleukins [62], as well as peptides such as endothelin. For example, TNF- $\alpha$, a prominent mediator of cancer pain [63-65], is known to strongly stimulate the release of several hematopoietic growth factors, including G-CSF and GM-CSF [66]. In turn, GM-CSF is known to synergistically enhance interferon-induced secretion of TNF- $\alpha$ from monocytes. Interestingly, GM-CSF and TNF- $\alpha$ synergize in enhancing the secretion of other cytokines, such as interleukin 1 (IL-1) [67]. That these interactions are clinically relevant is suggested by the observation that GM-CSF, interferons as well as diverse interleukins have been co-detected in synovial effusions of patients with rheumatoid arthritis [68]. The production of IL- $1 \alpha$, IL- $1 \beta$ as well as TNF- $\alpha$ by human mononuclear cells is stimulated by GM-CSF [69] and in turn, IL- 1 and TNF- $\alpha$ additively increase the production of G-CSF and GM-CSF at the mRNA level in human fibroblasts [70].

Endothelin 1 has gained a very prominent position in the pathophysiology of cancer pain and is amongst the few targets which have found its way from the bench to the bedside in the context of the treatment of cancer pain [71]. It is interesting to note that GM-CSF potentiates the production and release of endothelin 1 from human monocytes, suggesting that this might be another mechanism via which cancer pain can be potentiated [72]. Interestingly, a chemokine called the CC chemkokine L2 (CCL2), also known by the name MCP1, is known to be upregulated in splenic $\mathrm{T}$ lymphocytes of tumor-bearing animals by the concurrent production of GM-CSF by tumor

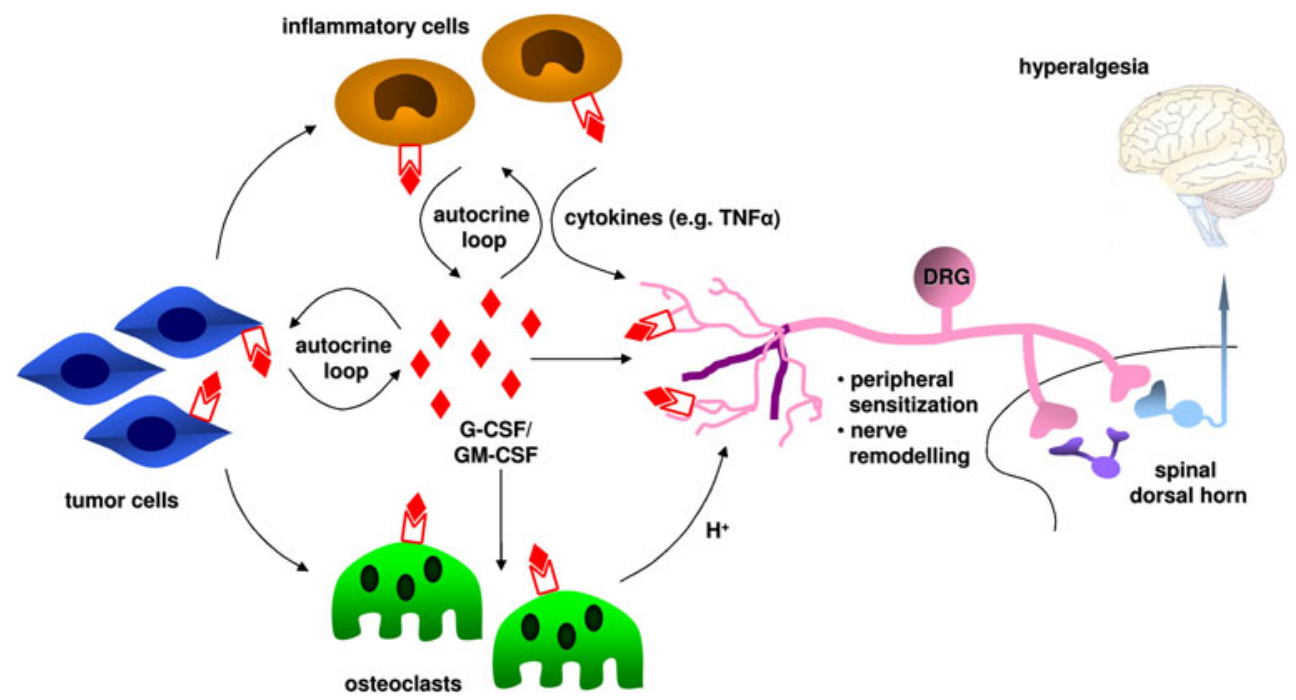

Fig. 3 Representation of potential local effects of G-CSF and GM$\mathrm{CSF}$ in the micromilieu of bone metastases in the context of cancer pain. G-CSF and GM-CSF are released by tumor cells and inflammatory cells and can act on peripheral endings of dorsal root ganglion neurons to produce sensitization, which is perceived as exaggerated pain (hyperalgesia). Furthermore, G-CSF and GM-CSF can evoke nerve remodelling (hypertrophy, sprouting of sensory nerves). Additionally, G-CSF and GM-CSF can recruit and stimulate inflammatory cells and induce bone resorption by osteoclasts. Inflammatory cells themselves sensitize peripheral nerve fibers by release of proinflammatory cytokines (e.g. TNF- $\alpha$, interleukins and endothelins), which may also contribute to nerve remodelling. Furthermore, osteoclasts can contribute to peripheral sensitization, in particular by release of protons. The proliferation of some types of tumor cells can be stimulated by local G-CSF and GM-CSF. In turn, tumor cells can contribute also indirectly to the sensitization of primary afferent nerve fibers by stimulating osteolysis and the local inflammatory response. Thus, hematopoietic growth factors may serve as central players in cancer pain via diverse, parallel mechanisms 
cells [73]. CCL2 immunoreactivity is present in tumors and high levels of CCL2 peptide have been reported in microperfusates from tumors. Interestingly, CCL2 directly sensitizes sensory nerves and leads to the upregulation of voltage-gated calcium channels, which may contribute to tumor-induced pain in the fibrosarcoma cancer model [74]. A summary of potential roles of G-CSF and GM-CSF in the cross-talk between tumor cells, inflammatory cells and sensory nerves in the context of bone cancer pain is given in Fig. 3.

\section{Therapeutic implications}

In the light of the cross-talk described above, it is very likely that synergistic associations between multiple paracrine mediators, which are present in the microenvironment of tumors and nerves, can contribute to tumor-nerve-immune interactions and to the pathogenesis of cancer-induced pain. Combination therapies targeting hematopoietic growth factor receptors and the above-mentioned peptides and chemokines therefore hold a high level of promise in the clinical management of cancer pain. In this regard, it is interesting to note that clinical trials are currently under way with various ligands and antagonists and chemokine receptors; furthermore, the elucidation of the crystal structure of the GM-CSFR complex holds promise for developing small molecule drugs which inhibit GM-CSFR-mediated functions in context of tumor-nerve interactions [75]. One antagonist of the GMCSF receptor, E21R [76], has already been tested in clinical trials for the treatment of solid tumors [77]. The effects of E21R on cancer pain, however, were not investigated. In the light of evidence from the studies discussed above, it seems worthwhile including pain as another parameter to be tested in future clinical studies.

\section{Conclusions}

Recent evidence indicates that hematopoietic growth factors, which are secreted at high levels in the microenvironment of tumors, are capable of sensitizing painsensing nerves in the vicinity of tumor cells and thereby evoking exaggerated sensitivity to tactile stimuli in tumorbearing mice. Complex interactions occur between hematopoietic growth factors and other known mediators of nerve sensitization, such as interleukins, TNF- $\alpha$ and endothelins, which promote pain hypersensitivity in diseased tissue. Taken together with reports on high levels of G-/GM-CSF in patients with rheumatoid arthritis, this indicates that intervention of G-/GM-CSF signaling may hold promise in the treatment of debilitating pain associated with cancer and rheumatoid arthritis.
Acknowledgements The authors thank Rose LeFaucheur for secretarial help, Donald A. Simone and Anthony Dickenson for sharing their know-how on tumor models of pain and the members of the Kuner lab for their contribution to the study cited and discussed in this review. This work was supported by grants from the Association of International Cancer Research and the Sander Stiftung to R.K.

Disclosure of potential conflicts of interest The authors declare no conflicts of interest related to this work.

Open Access This article is distributed under the terms of the Creative Commons Attribution Noncommercial License which permits any noncommercial use, distribution, and reproduction in any medium, provided the original author(s) and source are credited.

\section{References}

1. Portenoy RK, Lesage P (1999) Management of cancer pain. Lancet 353:1695-1700. doi:10.1016/S0140-6736(99)01310-0

2. Mantyh PW (2006) Cancer pain and its impact on diagnosis, survival and quality of life. Nat Rev Neurosci 7:797-809. doi:10.1038/nrn1914

3. Mantyh PW, Hunt SP (2004) Mechanisms that generate and maintain bone cancer pain. Novartis Found Symp 260:221-238, discussion 238-240, 277-229

4. Wacnik PW, Eikmeier LJ, Ruggles TR, Ramnaraine ML, Walcheck BK, Beitz AJ, Wilcox GL (2001) Functional interactions between tumor and peripheral nerve: morphology, algogen identification, and behavioral characterization of a new murine model of cancer pain. J Neurosci 21:9355-9366

5. Hamilton JA (2008) Colony-stimulating factors in inflammation and autoimmunity. Nat Rev Immunol 8:533-544. doi:10.1038/ nri2356

6. Schweizerhof M, Stosser S, Kurejova M, Njoo C, Gangadharan V, Agarwal N, Schmelz M, Bali KK, Michalski CW, Brugger S, Dickenson A, Simone DA, Kuner R (2009) Hematopoietic colony-stimulating factors mediate tumor-nerve interactions and bone cancer pain. Nat Med 15:802-807. doi:10.1038/nm.1976

7. Vairo G, Hamilton JA (1991) Signalling through CSF receptors. Immunol Today 12:362-369

8. Kaushansky K (2006) Lineage-specific hematopoietic growth factors. N Engl J Med 354:2034-2045. doi:10.1056/ NEJMra052706

9. Hucho T, Levine JD (2007) Signaling pathways in sensitization: toward a nociceptor cell biology. Neuron 55:365-376. doi:10.1016/j.neuron.2007.07.008

10. Jin X, Morsy N, Winston J, Pasricha PJ, Garrett K, Akbarali HI (2004) Modulation of TRPV1 by nonreceptor tyrosine kinase, c-Src kinase. Am J Physiol Cell Physiol 287:C558-C563. doi:10.1152/ajpcell.00113.2004

11. Basbaum AI, Bautista DM, Scherrer G, Julius D (2009) Cellular and molecular mechanisms of pain. Cell 139:267-284. doi:10.1016/j.cell.2009.09.028

12. Panopoulos AD, Watowich SS (2008) Granulocyte colonystimulating factor: molecular mechanisms of action during steady state and 'emergency' hematopoiesis. Cytokine 42:277-288. doi:10.1016/j.cyto.2008.03.002

13. Balonov K, Khodorova A, Strichartz GR (2006) Tactile allodynia initiated by local subcutaneous endothelin-1 is prolonged by activation of TRPV-1 receptors. Exp Biol Med Maywood $231: 1165-1170$ 
14. Wong GY, Gavva NR (2009) Therapeutic potential of vanilloid receptor TRPV1 agonists and antagonists as analgesics: Recent advances and setbacks. Brain Res Rev 60:267-277. doi:10.1016/j. brainresrev.2008.12.006

15. Bolcskei K, Helyes Z, Szabo A, Sandor K, Elekes K, Nemeth J, Almasi R, Pinter E, Petho G, Szolcsanyi J (2005) Investigation of the role of TRPV1 receptors in acute and chronic nociceptive processes using gene-deficient mice. Pain 117:368-376. doi:10.1016/j.pain.2005.06.024

16. Szabo A, Helyes Z, Sandor K, Bite A, Pinter E, Nemeth J, Banvolgyi A, Bolcskei K, Elekes K, Szolcsanyi J (2005) Role of transient receptor potential vanilloid 1 receptors in adjuvantinduced chronic arthritis: in vivo study using gene-deficient mice. J Pharmacol Exp Ther 314:111-119. doi:10.1124/jpet.104.082487

17. Gavva NR, Treanor JJ, Garami A, Fang L, Surapaneni S, Akrami A, Alvarez F, Bak A, Darling M, Gore A, Jang GR, Kesslak JP, Ni L, Norman MH, Palluconi G, Rose MJ, Salfi M, Tan E, Romanovsky AA, Banfield C, Davar G (2008) Pharmacological blockade of the vanilloid receptor TRPV1 elicits marked hyperthermia in humans. Pain 136:202-210. doi:10.1016/j. pain.2008.01.024

18. Miao T, Wu D, Zhang $\mathrm{Y}$, Bo $\mathrm{X}$, Subang MC, Wang $\mathrm{P}$, Richardson PM (2006) Suppressor of cytokine signaling-3 suppresses the ability of activated signal transducer and activator of transcription-3 to stimulate neurite growth in rat primary sensory neurons. J Neurosci 26:9512-9519. doi:10.1523/ JNEUROSCI.2160-06.2006

19. Dziennis S, Alkayed NJ (2008) Role of signal transducer and activator of transcription 3 in neuronal survival and regeneration. Rev Neurosci 19:341-361

20. Ji RR, Baba H, Brenner GJ, Woolf CJ (1999) Nociceptive-specific activation of ERK in spinal neurons contributes to pain hypersensitivity. Nat Neurosci 2:1114-1119. doi:10.1038/16040

21. Zhuang ZY, Xu H, Clapham DE, Ji RR (2004) Phosphatidylinositol 3-kinase activates ERK in primary sensory neurons and mediates inflammatory heat hyperalgesia through TRPV1 sensitization. J Neurosci 24:8300-8309. doi:10.1523/JNEURO SCI.2893-04.2004

22. Pezet S, Spyropoulos A, Williams RJ, McMahon SB (2005) Activity-dependent phosphorylation of Akt/PKB in adult DRG neurons. Eur J Neurosci 21:1785-1797. doi:10.1111/j.14609568.2005.04011.x

23. al-Aoukaty A, Giaid A, Sinoff C, Ho AD, Maghazachi AA (1994) Priming effects of granulocyte-macrophage colony-stimulating factor are coupled to cholera toxin-sensitive guanine nucleotide binding protein in human T lymphocytes. Blood 83:1299-1309

24. Wang S, Dai Y, Fukuoka T, Yamanaka H, Kobayashi K, Obata K, Cui X, Tominaga M, Noguchi K (2008) Phospholipase C and protein kinase A mediate bradykinin sensitization of TRPA1: a molecular mechanism of inflammatory pain. Brain 131:12411251. doi:10.1093/brain/awn060

25. Taiwo YO, Levine JD (1991) Further confirmation of the role of adenyl cyclase and of cAMP-dependent protein kinase in primary afferent hyperalgesia. Neuroscience 44:131-135

26. Ferreira SH, Nakamura M (1979) I - Prostaglandin hyperalgesia, a cAMP/Ca2 + dependent process. Prostaglandins 18:179-190

27. Bhave G, Zhu W, Wang H, Brasier DJ, Oxford GS, RWt G (2002) cAMP-dependent protein kinase regulates desensitization of the capsaicin receptor (VR1) by direct phosphorylation. Neuron 35:721-731

28. Fitzgerald EM, Okuse K, Wood JN, Dolphin AC, Moss SJ (1999) cAMP-dependent phosphorylation of the tetrodotoxin-resistant voltage-dependent sodium channel SNS. J Physiol 516(Pt 2):433-446

29. Bhave G, Hu HJ, Glauner KS, Zhu W, Wang H, Brasier DJ, Oxford GS, RWt G (2003) Protein kinase C phosphorylation sensitizes but does not activate the capsaicin receptor transient receptor potential vanilloid 1 (TRPV1). Proc Natl Acad Sci USA 100:12480-12485. doi:10.1073/pnas.2032100100

30. Woo DH, Jung SJ, Zhu MH, Park CK, Kim YH, Oh SB, Lee CJ (2008) Direct activation of transient receptor potential vanilloid 1 (TRPV1) by diacylglycerol (DAG). Mol Pain 4:42. doi:10.1186/ 1744-8069-4-42

31. Prescott ED, Julius D (2003) A modular PIP2 binding site as a determinant of capsaicin receptor sensitivity. Science 300:1284 1288. doi: $10.1126 /$ science. 1083646

32. Morenilla-Palao C, Planells-Cases R, Garcia-Sanz N, Ferrer-Montiel A (2004) Regulated exocytosis contributes to protein kinase C potentiation of vanilloid receptor activity. J Biol Chem 279:2566525672. doi:10.1074/jbc.M311515200

33. Nishimura M, Kaku K, Azuno Y, Okafuji K, Inoue Y, Kaneko T (1992) Stimulation of phosphoinositol turnover and protein kinase $\mathrm{C}$ activation by granulocyte-macrophage colony-stimulating factor in HL-60 cells. Blood 80:1045-1051

34. Kang HK, Lee HY, Lee YN, Jo EJ, Kim JI, Kim GY, Park YM, Min DS, Yano A, Kwak JY, Bae YS (2004) Up-regulation of phospholipase Cgamma1 and phospholipase D during the differentiation of human monocytes to dendritic cells. Int Immunopharmacol 4:911-920. doi:10.1016/j.intimp.2004.04.001

35. Veis N, Hamilton JA (1991) GM-CSF and IL-3 stimulate diacylglycerol generation in murine bone marrow-derived macrophages. Biochem Biophys Res Commun 179:586-591

36. Evans SW, Rennick D, Farrar WL (1987) Identification of a signal-transduction pathway shared by haematopoietic growth factors with diverse biological specificity. Biochem J 244:683691

37. Baxter GT, Miller DL, Kuo RC, Wada HG, Owicki JC (1992) PKC epsilon is involved in granulocyte-macrophage colony-stimulating factor signal transduction: evidence from microphysiometry and antisense oligonucleotide experiments. Biochemistry 31:10950 10954

38. Numazaki M, Tominaga T, Toyooka H, Tominaga M (2002) Direct phosphorylation of capsaicin receptor VR1 by protein kinase Cepsilon and identification of two target serine residues. J Biol Chem 277:13375-13378. doi:10.1074/jbc.C200104200

39. Khasar SG, Lin YH, Martin A, Dadgar J, McMahon T, Wang D, Hundle B, Aley KO, Isenberg W, McCarter G, Green PG, Hodge CW, Levine JD, Messing RO (1999) A novel nociceptor signaling pathway revealed in protein kinase $\mathrm{C}$ epsilon mutant mice. Neuron 24:253-260

40. Hucho TB, Dina OA, Levine JD (2005) Epac mediates a cAMPto-PKC signaling in inflammatory pain: an isolectin $\mathrm{B} 4(+)$ neuron-specific mechanism. J Neurosci 25:6119-6126. doi:10.1523/JNEUROSCI.0285-05.2005

41. Wang C, Gu Y, Li GW, Huang LY (2007) A critical role of the cAMP sensor Epac in switching protein kinase signalling in prostaglandin E2-induced potentiation of $\mathrm{P} 2 \mathrm{X} 3$ receptor currents in inflamed rats. J Physiol 584:191-203. doi:10.1113/jphy siol.2007.135616

42. Corey SJ, Burkhardt AL, Bolen JB, Geahlen RL, Tkatch LS, Tweardy DJ (1994) Granulocyte colony-stimulating factor receptor signaling involves the formation of a three-component complex with Lyn and Syk protein-tyrosine kinases. Proc Natl Acad Sci USA 91:4683-4687

43. Ward AC, Monkhouse JL, Csar XF, Touw IP, Bello PA (1998) The Src-like tyrosine kinase Hck is activated by granulocyte colony-stimulating factor (G-CSF) and docks to the activated G-CSF receptor. Biochem Biophys Res Commun 251:117-123. doi:10.1006/bbrc.1998.9441

44. Kroger N, Renges H, Kruger W, Gutensohn K, Loliger C, Carrero I, Cortes L, Zander AR (2000) A randomized comparison of once versus twice daily recombinant human granulocyte colony- 
stimulating factor (filgrastim) for stem cell mobilization in healthy donors for allogeneic transplantation. Br J Haematol 111:761-765

45. de la Rubia J, Martinez C, Solano C, Brunet S, Cascon P, Arrieta R, Alegre A, Bargay J, de Arriba F, Canizo C, Lopez J, Serrano D, Verdeguer A, Torrabadella M, Diaz MA, Insunza A, de la Serna J, Espigado I, Petit J, Martinez M, Benlloch L, Sanz M (1999) Administration of recombinant human granulocyte colony-stimulating factor to normal donors: results of the Spanish National Donor Registry. Spanish Group of AlloPBT. Bone Marrow Transplant 24:723-728. doi:10.1038/sj. bmt.1701977

46. De Placido S, Lauria R, Carlomagno C, Perrone F, De Laurentiis M, Gallo C, Martignetti A, Bellelli T, Limite G, Petrella G, Bianco AR (1999) The impact of schedule on acute toxicity and doseintensity of high-dose chemotherapy with epirubicin and cyclophosphamide plus colony stimulating factors in advanced breast cancer. Int J Oncol 15:339-346

47. Bonilla MA, Dale D, Zeidler C, Last L, Reiter A, Ruggeiro M, Davis M, Koci B, Hammond W, Gillio A et al (1994) Long-term safety of treatment with recombinant human granulocyte colonystimulating factor (r-metHuG-CSF) in patients with severe congenital neutropenias. Br J Haematol 88:723-730

48. Froberg MK, Garg UC, Stroncek DF, Geis M, McCullough J, Brown DM (1999) Changes in serum osteocalcin and bonespecific alkaline phosphatase are associated with bone pain in donors receiving granulocyte-colony-stimulating factor for peripheral blood stem and progenitor cell collection. Transfusion 39:410-414

49. Duda RJ Jr, O'Brien JF, Katzmann JA, Peterson JM, Mann KG, Riggs BL (1988) Concurrent assays of circulating bone Gla-protein and bone alkaline phosphatase: effects of sex, age, and metabolic bone disease. J Clin Endocrinol Metab 66:951-957

50. Mantyh PW, Clohisy DR, Koltzenburg M, Hunt SP (2002) Molecular mechanisms of cancer pain. Nat Rev Cancer 2:201209. doi: $10.1038 / \mathrm{nrc} 747$

51. Fulfaro F, Casuccio A, Ticozzi C, Ripamonti C (1998) The role of bisphosphonates in the treatment of painful metastatic bone disease: a review of phase III trials. Pain 78:157-169

52. Carvalho B, Clark DJ, Angst MS (2008) Local and systemic release of cytokines, nerve growth factor, prostaglandin $\mathrm{E} 2$, and substance $\mathrm{P}$ in incisional wounds and serum following cesarean delivery. J Pain 9:650-657. doi:10.1016/j. jpain.2008.02.004

53. Angst MS, Clark JD, Carvalho B, Tingle M, Schmelz M, Yeomans DC (2008) Cytokine profile in human skin in response to experimental inflammation, noxious stimulation, and administration of a COX-inhibitor: a microdialysis study. Pain 139:15-27. doi:10.1016/j.pain.2008.02.028

54. Liang D, Shi X, Qiao Y, Angst MS, Yeomans DC, Clark JD (2008) Chronic morphine administration enhances nociceptive sensitivity and local cytokine production after incision. Mol Pain 4:7. doi:10.1186/1744-8069-4-7

55. Feldmann M, Brennan FM, Maini RN (1996) Rheumatoid arthritis. Cell 85:307-310

56. Kokkonen H, Soderstrom I, Rocklov J, Hallmans G, Lejon K, Rantapaa Dahlqvist S (2010) Up-regulation of cytokines and chemokines predates the onset of rheumatoid arthritis. Arthritis Rheum 62:383-391. doi:10.1002/art.27186

57. Hitchon CA, Alex P, Erdile LB, Frank MB, Dozmorov I, Tang Y, Wong K, Centola M, El-Gabalawy HS (2004) A distinct multicytokine profile is associated with anti-cyclical citrullinated peptide antibodies in patients with early untreated inflammatory arthritis. J Rheumatol 31:2336-2346

58. Cook AD, Braine EL, Campbell IK, Rich MJ, Hamilton JA (2001) Blockade of collagen-induced arthritis post-onset by antibody to granulocyte-macrophage colony-stimulating factor
(GM-CSF): requirement for GM-CSF in the effector phase of disease. Arthritis Res 3:293-298

59. Eyles JL, Hickey MJ, Norman MU, Croker BA, Roberts AW, Drake SF, James WG, Metcalf D, Campbell IK, Wicks IP (2008) A key role for G-CSF-induced neutrophil production and trafficking during inflammatory arthritis. Blood 112:5193-5201. doi:10.1182/blood-2008-02-139535

60. Lawlor KE, Campbell IK, Metcalf D, O'Donnell K, van Nieuwenhuijze A, Roberts AW, Wicks IP (2004) Critical role for granulocyte colony-stimulating factor in inflammatory arthritis. Proc Natl Acad Sci USA 101:11398-11403. doi:10.1073/ pnas.0404328101

61. Cornish AL, Campbell IK, McKenzie BS, Chatfield S, Wicks IP (2009) G-CSF and GM-CSF as therapeutic targets in rheumatoid arthritis. Nat Rev Rheumatol 5:554-559. doi:10.1038/ nrrheum.2009.178

62. Andratsch M, Mair N, Constantin CE, Scherbakov N, Benetti C, Quarta S, Vogl C, Sailer CA, Uceyler N, Brockhaus J, Martini R, Sommer C, Zeilhofer HU, Muller W, Kuner R, Davis JB, Rose-John S, Kress M (2009) A key role for gp130 expressed on peripheral sensory nerves in pathological pain. J Neurosci 29:13473-13483. doi:10.1523/JNEUROSCI.1822-09.2009

63. Honore P, Luger NM, Sabino MA, Schwei MJ, Rogers SD, Mach DB, O'Keefe PF, Ramnaraine ML, Clohisy DR, Mantyh PW (2000) Osteoprotegerin blocks bone cancer-induced skeletal destruction, skeletal pain and pain-related neurochemical reorganization of the spinal cord. Nat Med 6:521-528

64. Wacnik PW, Eikmeier LJ, Simone DA, Wilcox GL, Beitz AJ (2005) Nociceptive characteristics of tumor necrosis factoralpha in naive and tumor-bearing mice. Neuroscience 132:479 491

65. Constantin CE, Mair N, Sailer CA, Andratsch M, Xu ZZ, Blumer MJ, Scherbakov N, Davis JB, Bluethmann H, Ji RR, Kress M (2008) Endogenous tumor necrosis factor alpha (TNFalpha) requires TNF receptor type 2 to generate heat hyperalgesia in a mouse cancer model. J Neurosci 28:5072-5081. doi:10.1523/ JNEUROSCI.4476-07.2008

66. Dedhar S, Gaboury L, Galloway P, Eaves C (1988) Human granulocyte-macrophage colony-stimulating factor is a growth factor active on a variety of cell types of nonhemopoietic origin. Proc Natl Acad Sci USA 85:9253-9257

67. Danis VA, Franic GM, Rathjen DA, Brooks PM (1991) Effects of granulocyte-macrophage colony-stimulating factor (GMCSF), IL-2, interferon-gamma (IFN-gamma), tumour necrosis factor-alpha (TNF-alpha) and IL-6 on the production of immunoreactive IL-1 and TNF-alpha by human monocytes. Clin Exp Immunol 85:143-150

68. Xu WD, Firestein GS, Taetle R, Kaushansky K, Zvaifler NJ (1989) Cytokines in chronic inflammatory arthritis. II Granulocyte macrophage colony stimulating factor rheumatoid synovial effusions. J Clin Invest 83:876-882

69. Sisson SD, Dinarello CA (1988) Production of interleukin-1 alpha, interleukin-1 beta and tumor necrosis factor by human mononuclear cells stimulated with granulocyte-macrophage colony-stimulating factor. Blood 72:1368-1374

70. Seelentag W, Mermod JJ, Vassalli P (1989) Interleukin 1 and tumor necrosis factor-alpha additively increase the levels of granulocyte-macrophage and granulocyte colony-stimulating factor (CSF) mRNA in human fibroblasts. Eur J Immunol 19:209-212

71. Nelson J, Bagnato A, Battistini B, Nisen P (2003) The endothelin axis: emerging role in cancer. Nat Rev Cancer 3:110-116. doi:10.1038/nrc990

72. Salh B, Hoeflick K, Kwan W, Pelech S (1998) Granulocytemacrophage colony-stimulating factor and interleukin-3 potentiate interferon-gamma-mediated endothelin production by 
human monocytes: role of protein kinase C. Immunology 95:473-479

73. Owen JL, Lopez DM, Grosso JF, Guthrie KM, Herbert LM, Torroella-Kouri M, Iragavarapu-Charyulu V (2005) The expression of CCL 2 by T lymphocytes of mammary tumor bearers: role of tumor-derived factors. Cell Immunol 235:122-135

74. Khasabova IA, Stucky CL, Harding-Rose C, Eikmeier L, Beitz AJ, Coicou LG, Hanson AE, Simone DA, Seybold VS (2007) Chemical interactions between fibrosarcoma cancer cells and sensory neurons contribute to cancer pain. J Neurosci 27:1028910298

75. Hansen G, Hercus TR, McClure BJ, Stomski FC, Dottore M, Powell J, Ramshaw H, Woodcock JM, Xu Y, Guthridge M,
McKinstry WJ, Lopez AF, Parker MW (2008) The structure of the GM-CSF receptor complex reveals a distinct mode of cytokine receptor activation. Cell 134:496-507

76. Hercus TR, Bagley CJ, Cambareri B, Dottore M, Woodcock JM, Vadas MA, Shannon MF, Lopez AF (1994) Specific human granulocyte-macrophage colony-stimulating factor antagonists. Proc Natl Acad Sci USA 91:5838-5842

77. Olver IN, Hercus T, Lopez A, Vadas M, Somogyi AA, Doyle I, Foster DJ, Keefe D, Taylor A, Brown M, To LB, Cole J, Rawling T, Cambareri B, Myers M, Olszewski N, Bastiras S, Senn C, Hey A, Verma M, Wigley P (2002) A phase I study of the GM-CSF antagonist E21R. Cancer Chemother Pharmacol 50:171-178. doi:10.1007/s00280-002-0474-y 